\title{
OS CRIMES CIBERNÉTICOS NA LEGISLAÇÃO BRASILEIRA E SUA ABORDAGEM
}

\author{
Hugo Stéphano Rufino Belezzi, Gerson Faustino Rosa
}

Universidade do Oeste Paulista - UNOESTE, Curso de Direito, Presidente Prudente, SP. E-mail: hbelezzi@gmail.com

\section{RESUMO}

O presente artigo abordará os crimes cibernéticos trazendo seu conceito e definição em face ao ordenamento jurídico naatualidade para a tratativa sobre o delito em tela, os principais bens jurídicos protegidos que são violados através do cometimento deste, a legislação infraconstitucional que trata do referido, trazendo inserções e alterações na legislação em vigência, os tipos decrimes mais comuns na atualidade cometidos pela internet em referência a um crescimentoconsiderável decasos do tipo, onde se levará em conta a necessidade de estabelecer uma legislaçãomais específica e aplicada para coibir os criminosos que utilizam deste meio, com o intuito de trazer uma maior segurança jurídica para quem utiliza destemeio.

Palavras-chave: Crime cibernético, internet, legislação.

\section{CYBER CRIMES IN BRAZILIAN LEGISLATION AND ITS APPROACH}

\section{ABSTRACT}

This article will address cybercrime bringing its concept and definition in relation to the legal system today to dealings on the offense screen, the main protected legal interests that are violated by the commission of this, the infra-constitutional legislation dealing with the above, bringing inserts and changes in legislation in force, the most common types of crimes today committed the internet in reference to a considerable growth of cases like that, where it will take into account the need to establish a more specific and applied legislation to prevent criminals use this medium in order to bring greater legal certainty for those using this medium.

Keywords: Cybercrime, internet, Law.

\section{INTRODUÇÃO}

Com os avanços tecnológicos, que a cada dia trazem diversas utilidades a todos os indivíduos que usufruem cada vez mais a internet como meio de informação, de lazer, de estudos, de compra e venda dentre outras finalidades, atualmente pode-se obter acesso a ela não só pelos computadores, mas também pelos celulares, smartphones, tablets, entre outros instrumentos utilizados na rotina diária das pessoas.

Porém, apesar das incomplexidades e vantagens oferecidas pela internet, esse cenário também é favorável para a prática de crimes, em que cada vez mais as pessoas se valem desse meio para a realização dos mais variados tipos de delitos, pois com o surgimento da internet, esses já tipificados pelo Código Penal passaram a ser praticados também on-line, assim como surgiram novas modalidades que passaram a ser exercidas através da utilização deste meio.

Neste contexto, surgiram os designados crimes cibernéticos, que apesar de estarem cada vez mais presentes na realidade brasileira, carecem de legislação específica, onde houve uma pequena adequação aos dispositivos já existentes na legislação. Diante desse cenário, o presente artigo busca, primeiramente, elucidar o conceito dos crimes cibernéticos. Adiante, analisará uma abordagem de como o ordenamento jurídico brasileiro pode tratar da matériadiante da falta de legislação específica infraconstitucional e perante a nossa Carta Magna. 


\section{METODOLOGIA}

Para a elaboração deste artigo, foi utilizado o método lógico-dedutivoatravés da realização de pesquisas bibliográficasem livros doutrinários, revistas jurídicas, artigos científicos e a análise da legislação específica e sua interferência dentro do Código Penal em face desse novo meio para o cometimento de delitos.

\section{CRIMES CIBERNÉTICOS}

$\mathrm{Na}$ conjuntura atual, dos progressos tecnológicos na área da informática, surgiram os denominados crimes cibernéticos. No entanto, não existe uma nomenclatura padronizada para os respectivos delitos, por isso esses são intitulados também de crimes de informática, crimes tecnológicos, delitos computacionais, crimes digitais, crimes virtuais, crimes informáticos, crimes cometidos por meio eletrônico, entre outros. Apesar da falta do tipo legal, os referidos crimes correspondem a todas as condutas já tipificadas, praticadas com o uso de tecnologia.

Crime de informática propriamente dito é aquele praticado contra o sistema de informática ou através deste, compreendendo os crimes praticados contra o computador e seus acessórios e os perpetrados através de computador. Incluem-se nesse conceito os delitos praticados através da Internet, pois pressuposto para acessar a rede é a utilização de um computador. (CASTRO, 2003, p. 14).

Para discutir sobre o tema, primeiramente é importante explanar sobre o bem jurídico tutelado, perante aos crimes cibernéticos. Teceremos de início uma noção de bem jurídico, conforme dispõe um dos mais renomados doutrinadores (PRADO, 2003), que nos esclarece de que é trazido tanto pelos princípios constitucionais pertencentes à matéria penal como pelos princípios de Direito Penal constitucional que é de extrema relevância, eis que a moderna ciência penal imprescinde de uma base empírica, de um vínculo com a realidade que lhe propicie uma razão de existência. De acordo com o princípio da exclusiva proteção do bem jurídico, todo delito deve lesar ou pôr em perigo de lesão determinado bem jurídico.

O delito a ser abordado no presente trabalho tem como bem jurídico a ser tutelado a liberdade individual, onde o tipo penal está expresso no capítulo que regula os crimes contra a liberdade individual, previsto nos artigos 146 ao 154 do Decreto-Lei no 2.848 de 07 de dezembro de 1940 (Código Penal), em sua Seção IV - Dos Crimes contra a inviolabilidade dos Segredos, crimes estes previstos nos artigos 153 a 154 - B do referido código e tambémpodemos afirmar que é tutelada a privacidade das pessoas como a intimidade e vida privada, bem jurídico este albergado pelo texto constitucional em seu artigo 5ㅇ, inciso $X$.

Assim, diante do cenário atual, com a expansão acelerada da Internet, ficam cada vez mais latentes na sociedade os crimes ocorridos por meios de dispositivos eletrônicos, decorrentes do fácil acesso a informaçõesdiversas dos usuários que fazem uso da rede mundial de computadores para as mais variadas finalidades, desde o uso de informações de registros financeiros, em se tratando de trâmites comerciais via rede, até dados pessoais, em se tratando de informações vinculadas a administração pública e ao particular.

\section{PRINCÍPIOS PENAIS DE GARANTIA E OS CRIMES CIBERNÉTICOS}

Os princípios são fontes normativas do Direito que visam direcionar, nortear, traçar uma diretriz para que determinadas normas e regras sejam inseridas com um propósito mútuo em nosso ordenamento para a aplicação de leis e sua finalidade. Nesse aspecto de definição, autores renomados trazem em nossa doutrina conceitos práticos de princípios (ÁVILA, 2014, p. 102):

[...] princípios são normas imediatamente finalísticas. Eles estabelecem um fim a ser atingido. Como bem define Ota Weinberger, um fim é ideia que exprime uma orientação prática. Elemento constitutivo do fim é a fixação de um conteúdo como pretendido.

O princípio da dignidade humana, um dos mais importantes princípios aclamados em nossa Constituição Federal de 1988, que é inerente a todo e qualquer ser humano e pressuposto ao reconhecimento e proteção aos Direitos Fundamentais, nosremete a uma vertente como o direito à informação que está previsto no artigo 5o em determinados incisos da nossa Lei Maior ${ }^{1}$ (BRASIL. Constituição, 1988).

\footnotetext{
${ }^{1 "}$ Art. $5^{\circ}$ - Todos são iguais perante a lei, sem distinção de qualquer natureza, garantindo-se aos brasileiros e aos estrangeiros residentes
} 
Com relação ao artigo supracitado, se faz importante ressaltar o princípio da legalidade, que enuncia a premissa de que não há crime sem lei anterior que o defina e nem pena sem previsão legal, ou seja, nenhum crime poderá ser tipificado e nenhuma sanção poderá ser aplicada se não houver previsão legislativa.

O bem jurídico passa necessariamente pela analise do delito no tempo, tendo em vista a consideração de que o crime é uma ameaça de lesão a tal, no entendimento de Prado (2005, p. 274), de que este é um ente (dado ou valor social) material ou imaterial haurido do contexto social, de titularidade individual ou metaindividual reputado com essencial à coexistência e desenvolvimento do homem e, por isso, jurídico penalmente protegido.

Com relação aos crimes cibernéticos, pode-se dizer que a prática delitiva que se utiliza da internet como meio para atingir a finalidade ilícita, viola bens jurídicos garantidos por nossa Carta Magna como a intimidade, a liberdade de expressão, a privacidade, dentre outros de suma importância.

Todos esses incisos estão vinculados ao direito à informação e também à liberdade informática, pois se utiliza através de instrumentos desse meio para manter-se informado e também para comunicar a população. Consoante é suscitado às garantias fundamentais da propriedade intelectual, prevista no inciso IX e o Direito a intimidade e à vida privada em seu inciso $X$, direitos esses que foram tão aclamados em todo o processo histórico do nosso estado Democrático de Direito, mas que atualmente se encontram abalados perante o atual avanço tecnológico.

É importante destacar a diferença entre esses dois bens juridicamente tutelados em nossa Carta Magna(BRASIL. Constituição, 1988), pois o Direito a intimidade se refere à esfera intima do indivíduo, suas convicções, hábitos, dentre várias outras particularidades. Já em se tratando da vida privada, a nossa Constituição visa a proteger sua liberdade individual e familiar perante o meio externo e eventuais investigações.

no País a inviolabilidade do direito à vida, à liberdade, à igualdade, à segurança e à propriedade, nos termos seguintes:

IX - é livre a expressão da atividade intelectual, artística, científica e de comunicação, independentemente de censura ou licença;

$X$ - são invioláveis a intimidade, a vida privada, a honra e a imagem das pessoas, assegurado o direito a indenização pelo dano material ou moral decorrente de sua violação.

XXXIX - não há crime sem lei anterior que o defina, nem pena sem prévia cominação legal;
Esse conceito acompanha a definição por Alexandre de Moraes (2016, p. 122):

Assim, intimidade relacionase às relações subjetivas e de trato íntimo da pessoa, suas relações familiares e de amizade, enquanto vida privada envolve todos os demais relacionamentos humanos, inclusive os objetivos, tais como relações comerciais, de trabalho, de estudo etc.

No mesmo raciocínio o referido autor indica a necessidade de indenização por danos materiais e morais nos atos em que afrontam a dignidade da pessoa humana por violação ao direito da intimidade e da vida privada. E foi justamente nesse contexto que o legislativo elaborou a Lei no 12.737 de 30 de novembro 2012, decorrente ao escândalo envolvendo a atriz Carolina Dieckmann, cuja intimidade e privacidade foram violadas através da internet(BRASIL, 2012 ; CABETE, 2013).

Portanto, ao analisar as dificuldades em inserir esse tipo de delito em nosso ordenamento, podemos dizer que já existem leis esparsas que adentraram dispositivos no âmbito penal, mas estamos iniciando, em "passos curtos", uma nova realidade social inserida na Legislação Brasileira.

\section{LEGISLAÇÃO ESPECÍFICA SOBRE CRIMES CIBERNÉTICOS NO ORDENAMENTO JURÍDICO BRASILEIRO}

Considerando os delitos de caráter cibernético, nos quais o bem jurídico por ele tutelado, corolário em alguns direitos fundamentais elencados no tópico anterior, remete a dispositivos inseridos na legislação infraconstitucional, crimes estes definidos como próprios impróprios e mistos.

Segundo (VIANNA, 2003, p.23), Crimes informáticos próprios são aqueles em que o bem jurídico protegido pela norma penal é a inviolabilidade das informações automatizadas (dados). Temos como exemplo desse crime, a interceptação telemática ilegal, prevista no art. 10 da Lei $n$ o 9296/96 ${ }^{2}$ e nos artigos 313-A do $C P^{3}$

\footnotetext{
${ }^{2}$ Art. 10. Constitui crime realizar interceptação de comunicações telefônicas, de informática ou telemática, ou quebrar segredo da Justiça, sem autorização judicial ou com objetivos não autorizados em lei.
} 
e 313-B do $C P^{4}$.Aqui cabe uma crítica uma vez que este tipo de delito, nos casos onde há ausência de previsão legal, estes se tornam inadequados, tendo em vista a falta da tipicidade, que consiste em um dos elementos essenciais na conceituação do crime. Os Crimes informáticos impróprios são aqueles nos quais o computador é usado como instrumento para a execução do crime, porém, não há ofensa ao bem jurídico, inviolabilidade da informação automatizada (dados). Exemplos de crimes informáticos impróprios podem ser os crimes contra a honra; apologia ao crime ou criminoso art. 287 do CP;induzimento, instigação ou auxílio ao suicídio art. 122 do $\mathrm{CP}$, todos podendo ser cometidos, por exemplo, com o envio de um e-mail. Há também os mistos que consiste em crimes mais complexos em que, além da proteção da inviolabilidade dos dados, a norma visa a tutelar bem jurídico de natureza diversa.

A Lei n. 12.737/12 já mencionada no capitulo anterior, insere os artigos $154-A^{5}$ e $154-$

Pena: reclusão, de dois a quatro anos, e multa.

${ }^{3}$ Art. 313-A. Inserir ou facilitar, o funcionário autorizado, a inserção de dados falsos, alterar ou excluir indevidamente dados corretos nos sistemas informatizados ou bancos de dados da Administração Pública com o fim de obter vantagem indevida para si ou para outrem ou para causar dano:

Pena - reclusão, de 2 (dois) a 12 (doze) anos, e multa

${ }^{4}$ Art. 313-B. modificar ou alterar, o funcionário, sistema de informações ou programa de informática sem autorização ou solicitação de autoridade competente:

Pena - detenção, de 3 (três) meses a 2 (dois) anos, e multa.

${ }^{5}$ Art. 154-A. Invadir dispositivo informático alheio, conectado ou não à rede de computadores, mediante violação indevida de mecanismo de segurança e com o fim de obter, adulterar ou destruir dados ou informações sem autorização expressa ou tácita do titular do dispositivo ou instalar vulnerabilidades para obter vantagem ilícita:

Pena - detenção, de 3 (três) meses a 1 (um) ano, e multa.

$\S 1^{\circ}$ Na mesma pena incorre quem produz, oferece, distribui, vende ou difunde dispositivo ou programa de computador com o intuito de permitir a prática da conduta definida no caput.

$\S 2^{\circ}$ Aumenta-se a pena de um sexto a um terço se da invasão resulta prejuízo econômico.

$\S 3^{\circ}$ Se da invasão resultar a obtenção de conteúdo de comunicações eletrônicas privadas, segredos comerciais ou industriais, informações sigilosas, assim definidas em lei, ou o controle remoto não autorizado do dispositivo invadido:

Pena - reclusão, de 6 (seis) meses a 2 (dois) anos, e multa, se a conduta não constitui crime mais grave.

$\S 4^{\circ}$ Na hipótese do $\S 3^{\circ}$, aumenta-se a pena de um a dois terços se houver divulgação, comercialização ou transmissão a terceiro, a qualquer título, dos dados ou informações obtidos.

$\S 5^{\circ}$ Aumenta-se a pena de um terço à metade se o crime for praticado contra:

I - Presidente da República, governadores e prefeitos;

II - Presidente do Supremo Tribunal Federal;

III - Presidente da Câmara dos Deputados, do Senado Federal, de Assembleia Legislativa de Estado, da Câmara Legislativa do Distrito Federal ou de Câmara Municipal; ou
$B^{6}$ que se refereà invasão de dispositivo informático e a respectiva ação penal, além de alterar a redação dos artigos 266 - Interrupção ou perturbação de serviço telegráfico, telefônico, informático, telemático ou de informação de utilidade pública e 298 - falsificação de documento particular.

No entanto há tipos específicos dos crimes informáticos que se enquadram de certa forma, nos tipos do Código Penal como é o caso de furto art. 155 do $\mathrm{CP}$, crime contra o patrimônio, mas que devem ser analisadas as circunstâncias com certo cuidado. Há quem diga que quando se invade clandestinamente algum dispositivo informático com o fim de se copiar algum programa ou arquivo, não se está praticando furto, pois não seria subtração de coisa alheia móvel, afinal, oobjeto do crime seria coisa móvel? Sob essa vertente (VIANNA, 2013) analisa:

Há que se levar em conta, evidentemente, nestas circunstâncias, o dolo do agente. Se sua intenção era subtrair o disco rígido pelo valor patrimonial que $o$ dispositivo tem mesmo quando formatado, haverá furto; se, porém, buscava o conteúdo armazenado no disco, isto é, os dados, haverá invasão de dispositivo informático, sendo o furto crime-meio não apenado com base no princípio da consunção.

Por fim, devemos mencionar a Lei № 12.965, de 23 de abril de 2014, conhecida como Marco Civil da Internet, em que se versa sobre princípios, garantias, direitos e deveres para o uso da rede no Brasil, esta lei claramente influenciou toda a legislação penal subsequente, sendo capaz de alterar de forma vasta a atual situação jurídica conexa a crimes virtuais. Portanto, não podemos afirmar que o espaço cibernéticoseja isento de proteção jurídica,

IV - dirigente máximo da administração direta e indireta federal, estadual, municipal ou do Distrito Federal. “

\footnotetext{
${ }^{6}$ Art. 154-B. Nos crimes definidos no art. 154-A, somente se procede mediante representação, salvo se o crime é cometido contra a administração pública direta ou indireta de qualquer dos Poderes da União, Estados, Distrito Federal ou Municípios ou contra empresas concessionárias de serviços públicos."
} 
apesar desta proteção estar esparsa em nosso ordenamento.

\section{CONCLUSÃO}

Diante do exposto em relação ao avanço da tecnologia, do uso da internet e dos meios eletrônicos que incrustaram no cotidiano das pessoas, teve como consequência um aumento nos crimes relacionados a esse cenário. O Brasil começou a dar atenção a este tipo de delito, mas, ainda, se mostra atrasado por não possuir legislação específica no ordenamento para disciplinar os crimes cibernéticos.

Embora já tenham sido tomadas certas medidas emergenciais, como a elaboração de leis que normatizam algumas dessas condutas delituosas que ocorrem no meio virtual, há ainda um despreparo por parte das autoridades em face ao combate desse tipo de crime, em que se faz necessário um maior investimento na área de segurança da informação e treinamento especializado dos agentes para que haja uma persecução penal efetiva em face de este tipo de delito, até porque o atual Código Penal é de 1940, e nessa época não havia as tecnologias que são utilizadas atualmente. Por isso, existem condutas atípicas, que não podem ser punidas em decorrência do princípio da legalidade ou da reserva legal, sendo insuficientes para combater os crimes virtuais a aplicação das legislações vigentes. Como os referidos crimes ocorrem no mundo inteiro, sem respeitarem fronteiras, além da legislação específica, é necessário à adesão do Brasil em tratados internacionais que disciplinam sobre a matéria para adequação da legislação interna.

\section{REFERÊNCIAS}

ÁVILA, Humberto.Teoria dos princípios da definição à aplicação dos princípios jurídicos. 12 . ed. São Paulo: Malheiros, 2014.p. 102.

BRASIL. Constituição (1988).Constituição da República Federativa do Brasil de 1988. Disponível em: <http://www.planalto.gov.br/ccivil_03/Constituic ao/Constituicao.htm>. Acesso em: 12 jun. 2016. BRASIL. Código Penal. Decreto-Lei no 2.848, de 7 de dezembro de 1940 . Disponível em: <http://www.planalto.gov.br/ccivil_03/decretolei/Del2848compilado.htm>. Acesso em 12 jun. 2016.

BRASIL. Lei n.o 9.296 de 24 de julho de 1996, Regulamenta o inciso XII, parte final, do art. $5^{\circ}$ da Constituição Federal. Disponível em: <
http://www.planalto.gov.br/ccivil_03/leis/L9296. htm>. Acesso em: 18 jun. 2016.

BRASIL. Lei n.o 12.737 de 30 de novembro de 2012, que traz a tipificação criminal de delitos informáticos. Disponível em: <http://www.planalto.gov.br/ccivil_03/_ato20112014/2012/lei/l12737.htm >. Acesso em: 26 jun. 2016.

BRASIL. Lei n.o 12.965 de 23 de abril de 2014, Estabelece princípios, garantias, direitos e deveres para o uso da Internet no Brasil. em:

http://www.planalto.gov.br/ccivil_03/_ato20112014/2014/lei/l12965.htm>. Acesso em: 26 jun. 2016.

CABETE, Eduardo Luiz Santos. Lei Carolina Dieckmann: o novo crime de invasão de dispositivo informático. Revista Consultor Jurídico,4 de fev., 2013. Disponível em: <http://www.conjur.com.br/2013-fev-

04/eduardo-cabette-crime-invasao-dispositivoinformatico\#author>. Acesso em: 07 jul. 2016. CASTRO, Carla Rodrigues Araújo de.Crimes de Informática e seus Aspectos Processuais. 2.ed. Rio de Janeiro: Lumen Júris, 2003, p. 14.

MORAES, Alexandre de. Direito constitucional. 36. ed. São Paulo: Atlas, 2016.

PRADO, Luiz Regis. Bem jurídico-penal e constituição. 3. ed. São Paulo: RT, 2003.

Curso de direito penal brasileiro: parte geral, arts 10 ao 120. 5. ed. São Paulo: RT, 2005.

Curso de direito penal brasileiro. 9.ed. São Paulo: RT, 2012.v.3

VIANNA, Túlio; MACHADO, Felipe. Crimes informáticos. Belo Horizonte: Fórum, 2013. p. 65. VIANNA, Túlio Lima. Fundamentos de direito penal informático. 1. ed. Rio de Janeiro: Forense, 2003.

Recebido para publicação em 26/08/2016

Revisado em 01/09/2016

Aceito em 08/09/2016 